\title{
Overview on pathogenesis and histopathological observations of hyperostosis in two fish species; Scomberoides lysan (Forsskal, 1775) and Pomacanthus sextriatus (Cuvier, 1831) collected from El- Jubail province, Saudi Arabia
}

\author{
Mahmoud A. Mahmoud' ${ }^{1}$, Mustafa Ibrahim ${ }^{2}$ \\ ${ }^{1}$ Department of Pathology, Faculty of veterinary Medicine, Cairo University, Egypt, ${ }^{2}$ Ministry of Agriculture, Fish Welfare Branch, Saudi Arabia; Animal Health \\ Research institute, Egypt \\ Keywords: hyperostosis, scomberoides lysan, pomacanthus sextriatus, histopathology \\ https://doi.org/10.48045/001c.31528
}

Bulletin of the European Association of Fish Pathologists

Vol. 41, Issue 3, 2021

\begin{abstract}
During years 2012 to 2018, two fish species, doublespotted queenfish (Scomberoideslysan) and sixbar angelfish (Pomacanthus sextriatus) were regularly examined during filleting processing in fish markets at Jubail province, Saudi Arabia. The routine fish inspection of the fillet- by products (fish skeletons) of these two species showed prominent and frequent hard circumscribed ossified masses attached to the spines. In Scomberoides lysan 60\% of the examined fishes were affected and the hyperosteoid overgrowths were noticed in both haemal and neural spines. In Pomacanthus sextriatus 10\% showed nearly the same lesion but it was mainly observed in the neural spines. In gross examination, the swelling appeared very hard, round and smooth; the cut section showed grayish- white, granular, greasy and hard central contents. In histopathological examination, the hard masses showed hyperosteoid bony tissue with variable degrees of ossification surrounded with peripheral fibrous tissue capsule containing dilated lymph and blood vessels and accompanied with edema. The underlying tissue was a thick layer of acellular calcified bony tissue while the central area of the swelling was honeycomb in its appearance with cavities filled with blood and adipocytes together with golden brown pigments, hemosiderin. Our study concluded that hyperostosis occurs at high prevalence rates in S. lysan and P. sextriatus with characteristic histopathological lesions.
\end{abstract}

\section{Introduction}

Hyperostosis in fish is referred to excessive growth and swelling of bone tissue in a particular part in the skeleton and usually accompanied with periosteal ossification (Gualdie and Czochanska 1990; Smith-Vaniz and Carpenter 2007; Giarratana et al. 2012). It is not a new lesion and has been recorded in many fish species, especially in marine fishes (Grabda 1982; Smith-Vaniz, Kaufman, and Glowacki 1995a; Jawad 2013). In some of the earlier studies it has been suggested that pollution, diseases and possibly evidence of genetic predisposition may be the cause of hyperostosis (McGrouther 1994; SmithVaniz, Kaufman, and Glowacki 1995b). Such studies noted that the condition doesn't effect the edibility of the fish; on the other hand, Meunier, Gaudant, and Bonelli (2010) studied the histological features of hyperostosis in Lepidopus albyi and found that the hyperostosis constituted spongy bone characteristics. From a pathological point of view, they described the lesion 
as an increase of the periosteal osteogenesis combined with resorption that creates many vascular cavities. However, many hypotheses may explain the cause of this hyperostotic phenomenon but they remain hypothetical; genetic factors seem the more accepted cause in the earlier studies. Thus, the causes and consequences of hyperostosis remain unclear.

In our study, the prevalence, gross lesions and histopathological examination of hyperostosis were studied in two fish species, Scomberoides lysan (native Arabic name: Dalaa) and Pomacantbus sextriatus (native Arabic name: Anfoos) collected from fish markets during routine inspection of filleting processes at El- Jubail province, Saudi Arabia. The aim of this study was to examine the pathological changes of hyperostosis in these two fish species.

\section{Materials and methods}

\subsection{Fish collection}

During routine veterinary inspections at fish markets during the filleting process in Jubail province (' $27^{\circ} 57.9^{\prime}$ " $\mathrm{N}$ and '49 40' 43.4" E), 2500 bone skeletons of Scomberoides lysan (Dalaa fish) and 250 of Pomacanthus sextriatus (Anfoos fish) were grossly examined between January 2012 to December 2018.

\subsection{Pathological examination}

\subsubsection{GROSS EXAMINATION}

All fish skeletons were examined for the presence of bone swelling in spines and/or vertebrae. The prevalence rate of affected fish were recorded and representative samples examined radiographically.

\subsubsection{HISTOPATHOLOGICAL EXAMINATION}

For histopathological studies, tissue sections were prepared according to the established method mentioned by Roberts, Smail, and Munro (2012); fresh bone specimens from the affected fish were fixed immediately in $10 \%$ neutral buffered formalin, decalcified in formic acid and embedded in paraffin. Five $\mu \mathrm{m}$ thick sections were obtained and then stained with the routine Hematoxylin and Eosin dye, and other necessary histochemical stains (Alizaren red and Perl's Prussian blue). The lesions were evaluated and photographed under a light microscope (Olympus BX50).

\section{Results}

\subsection{Pathological results}

\subsubsection{GROSS FINDINGS}

The examined $S$. lysan were between $75 \mathrm{~cm}$ to $120 \mathrm{~cm}$ total length and weighed between $1.5 \mathrm{~kg}$ to $4.5 \mathrm{~kg}$. The hyperosteoid lesion in these fish appeared as multifocal, very hard, round and smooth pedunculated bony swellings in both neural and haemal spines attached to the base of the vertebral column (Figures $\underline{1,2}$ and 3 ). In radiographic findings, the intensity of bony tissue varied where the hyperosteoid swelling in the haemal spine appeared smaller and with lower 

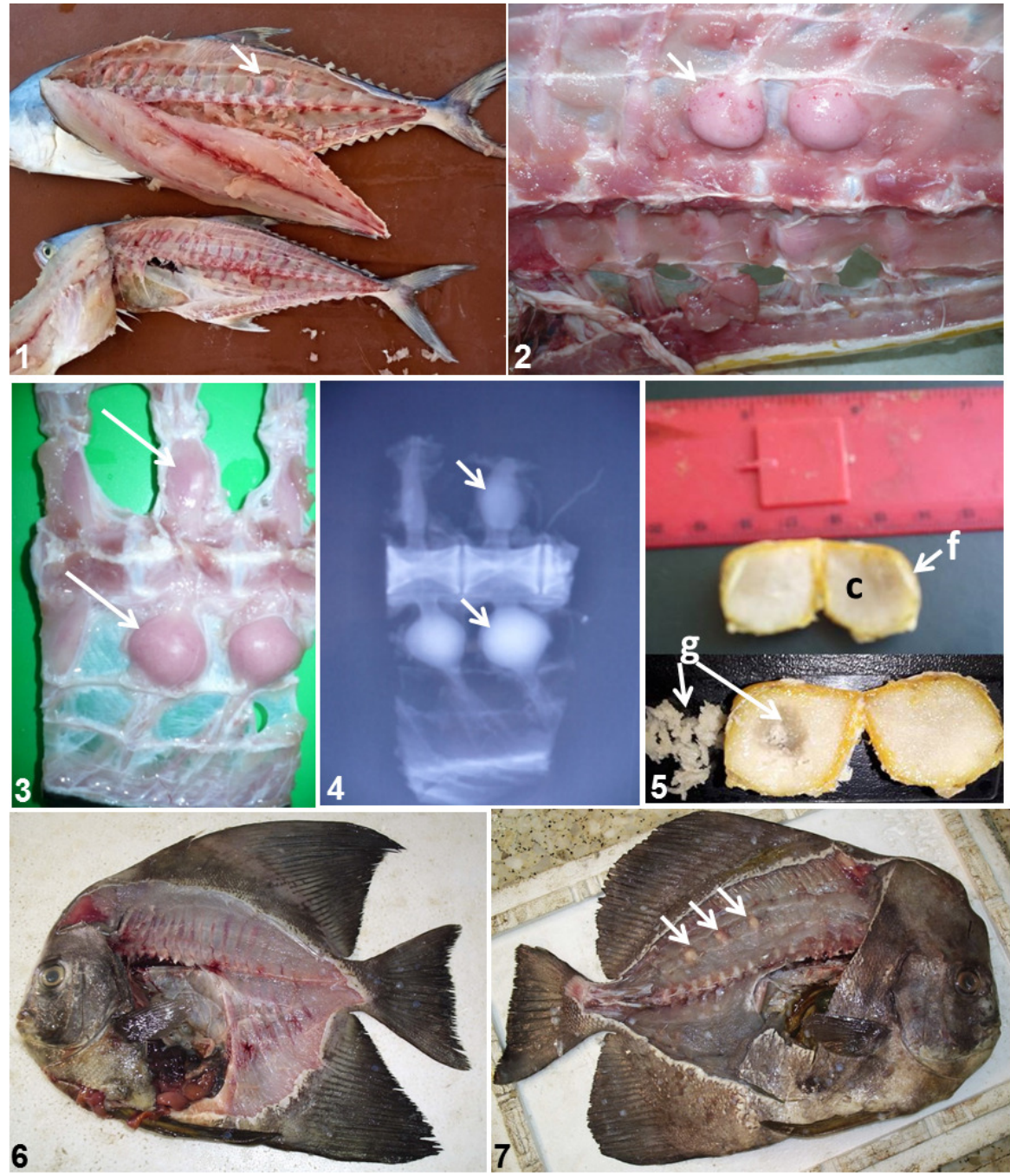

Figures 1-7. 1. Scomberoides lysan fish showing multiple circumscribed hyperosteoid tissue in the neural spines (arrow) compared with the normal fish (lower photo). 2. Skeleton of Scomberoides lysan showing two hyperosteoid balls- shaped masses (arrow) in the neural spine; attached to the vertebrae and covered with delicate and glistening fibrous capsule with red dots of congested blood capillaries on its surface. 3. Hyperostoid tissue of variable sizes in both neural and haemal spines. 4. Radiographic image of hyperosteoid tissue with variable degrees of calcification intensities; note the decreased calcification intensity in the upper small sized osteoid mass in comparison to the lower larger masses (arrows). 5. Cross section in the hyperosteoid tissue showing central area of greasy calcified substance (c), granular in nature (g); bounded by fibrous capsule (f). 6. Normal Pomacanthus sextriatus fish without hyperostosis. 7. Pomacanthus sextriatus fish with multiple hyperosteoid circumscribed masses attached to neural spines and not attached to the vertebrae (arrows).

intensity than the bone tissue while those in neural spines were larger and with more condensed calcification (Figure 4). The diameter of the swellings ranged from $1.5-2.0 \mathrm{~cm}$ in diameter; the cut surface appeared rounded and showed hard osseous tissue in the periphery covered with fibrous capsule containing greasy hard white granules in its centers (Figure 5). The granulated greasy central contents seem to comprise of fat necrosis with calcification. The number of the hyperosteoid swellings ranged from $5 /$ fish (in small sized fish) to 30 (in larger sized fish). In all fishes, the hyperostotic lesion appeared in its mature hard ossified tissue state without evidence of staging of the lesion. 


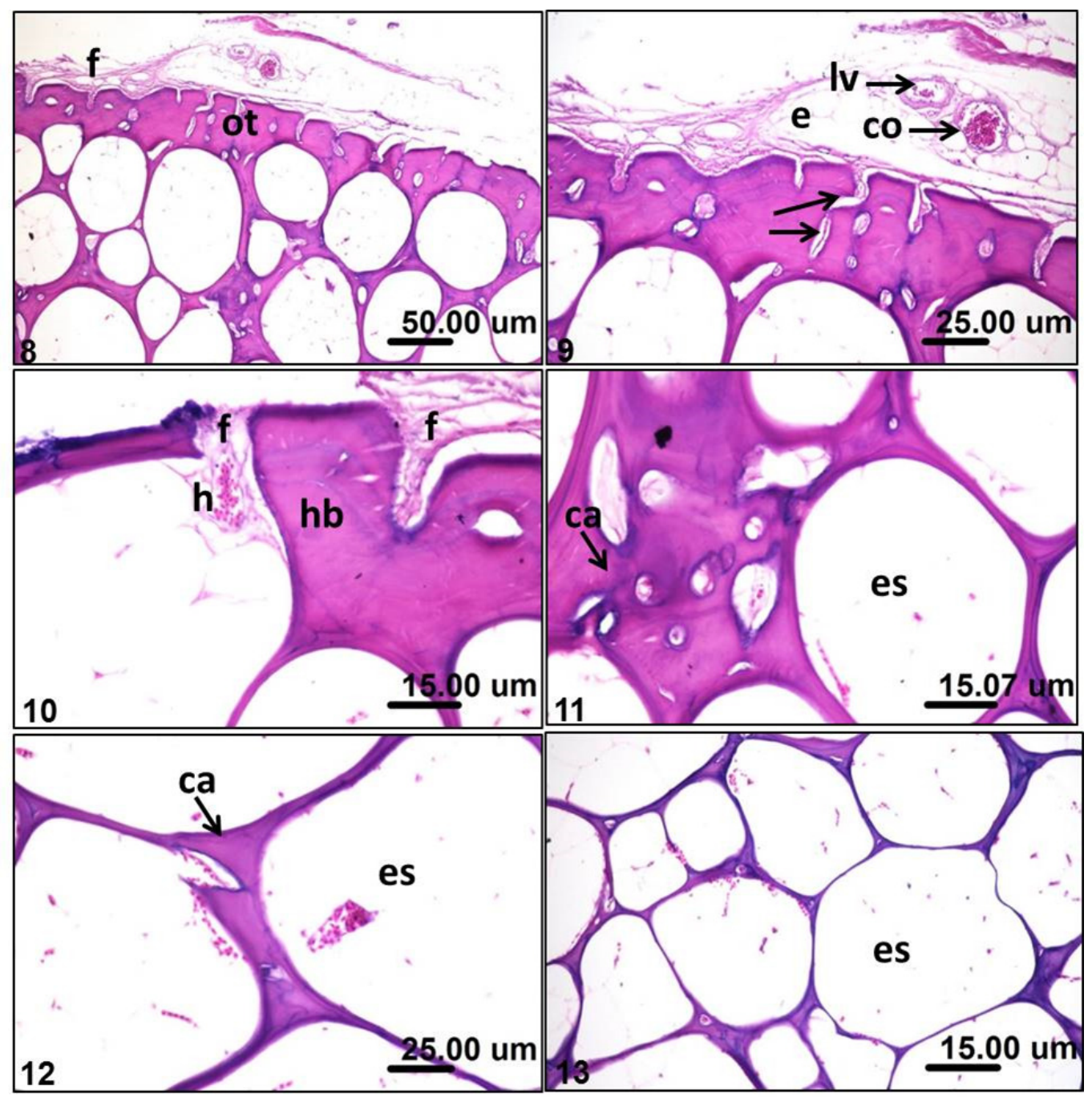

Figures 8-13. Histopathological section of hyperosteoid mass in acellular bony tissue of the spines showing: 8. External layer of periosteal tissue and thin layer of fibrous connective tissue capsule $(\mathrm{f})$ followed by osteoid tissue (ot) with areas of empty spaces underneath. 9. The fibrous capsule containing congested blood vessel (co) and dilated lymph vessel (lv) surrounded by edema (e); the hyperosteoid tissue penetrated with the periosteal tissue (arrows). 10. Hyperostoid bony tissue surrounded by periosteal and fibrous connective tissue $(\mathrm{f})$ and focal area of hemorrhage $(\mathrm{h})$. 11. Hyperostoid bony tissue with prominent blue colored areas of calcification (ca) and prominent interlacing empty spaces (es). 12. Acellular calcified hyperosteoid tissue (ca) showing areas of hemorrhage in the surrounding empty spaces (es). 13. Multiple empty spaces (es) with variable sizes in the acellular hyperosteoid tissue.

The examined P. sextriatus were 25 to $40 \mathrm{~cm}$ total length and 0.5 to $4 \mathrm{~kg}$ weight. The hyperosteoid swellings in these fish appeared very similar as that observed in $S$. lysan, but with smaller diameters; found mainly in the neural spines without attachment to the vertebrae (Figures 6 and 7 ).

\subsubsection{HISTOPATHOLOGICAL FINDINGS}

Histopathological sections of hyperosteoid mass in the examined fishes showed prominent acellular bony tissue formed of an external layer of periosteal tissue with a characteristic thin layer of fibroblast cells forming a capsule followed by a thick layer of osteoid tissue with areas of empty spaces underneath (Figure 8). The fibrous capsule showed congested blood vessels and dilated lymph vessels surrounded with edema and the hyperosteoid tissue penetrated by the periosteal tissue (Figure 9). Focal areas of hemorrhages were noticed in the 


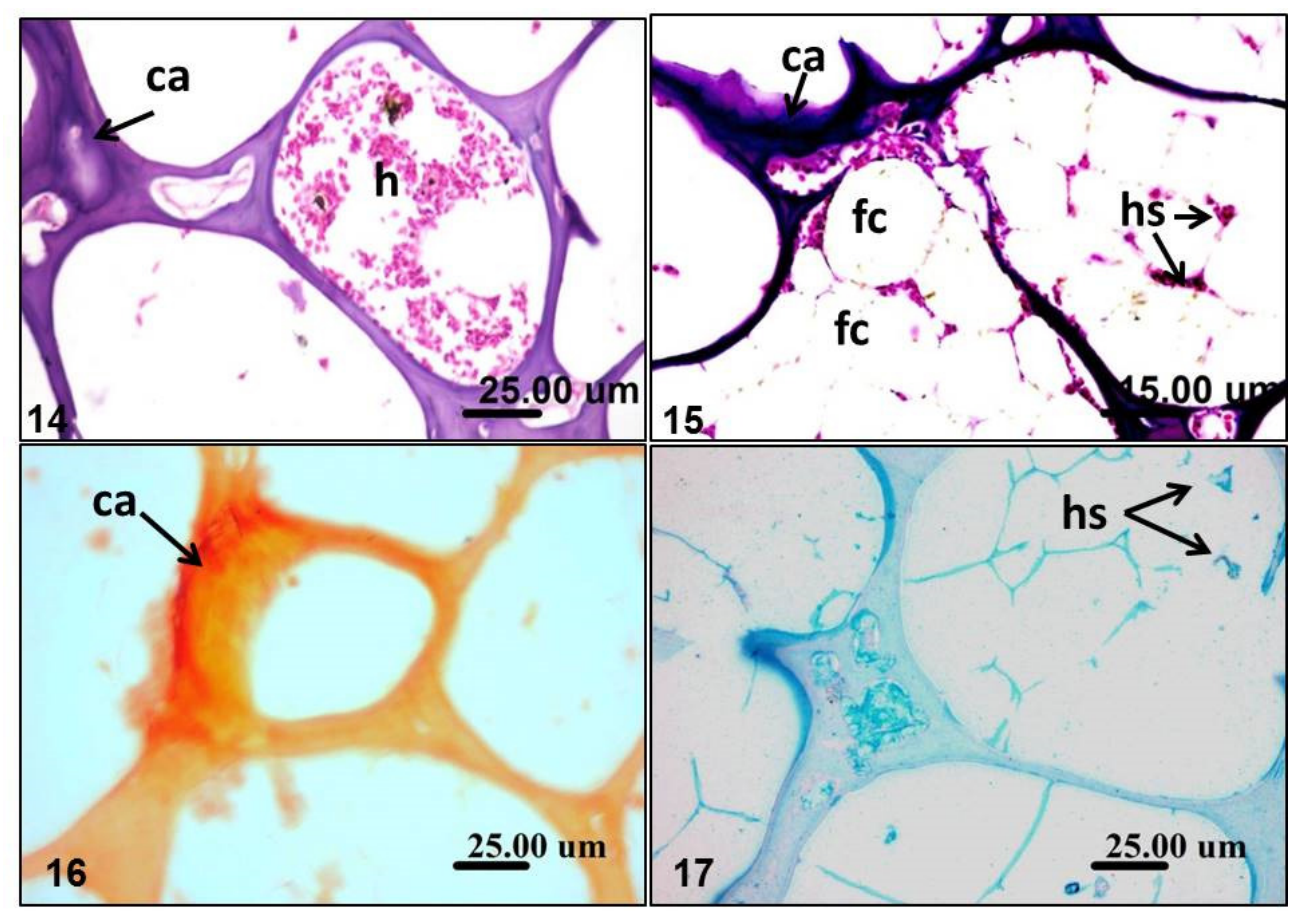

Figures 14-17. Histopathological section of hyperosteoid mass in acellular bony tissue of the spines of Scomberoides lysan and Pomacanthus sextriatus showing 14. Calcified acellular hyperosteoid tissue (ca) with prominent spaces filled with hemorrhage (h). 15. Cavities of hyperosteoid acellular bone filled with fat cells ( $\mathrm{fc}$ ); with deep blue calcification (ca); hemorrhages and golden- brown hemosiderin pigments (hs).16. Calcified acellular hyperosteoid tissue (ca), confirmed histochemically by Alizaren red stain (red color). 17. Hemosiderin pigments (hs) stained blue by Perl's Prussian blue stain.

capsular layer (Figure 10). The hyperosteoid tissue appeared with prominent blue colored calcified areas with interlacing empty vacuolar spaces (Figure 11). Areas of hemorrhages were sometimes observed in between the calcified hyperosteoid tissue (Figure 12). The empty spaces were variable in size. The characteristic honeycomb appearance was the common finding (Figure 13). Some of these spaces sometimes filled with hemorrhage together with hemosiderin pigments deposition (Figure 14); while others were impacted with adipocytes (fat cells). The fat cells appeared shadowy and without prominent nuclei indicating fat necrosis. The cells in such areas were surrounded with hemorrhages and hemosiderin pigments together with minute congested capillaries. Prominent deep blue calcification was also noticed (Figure 15). The calcification and hemosiderin pigments deposition was confirmed histochemically using Alizaren red and Perl's Prussian blue stains respectively (Figure 16 and 17).

\section{Discussion}

In comparison to mammals, most of the bone tissue of teleosts is entirely devoid of osteocytes (Meunier 1987, 1989; Huysseune 2000; Witten et al. 2004; Shahar and Dean 2013; Davesne et al. 2019). In our study, the bone swelling (hyperostosis) in the two examined fish species Scomberoides lysan and Pomacanthus sextriatus showed multiple acellular bone overgrowth without prominent osteoblast cell proliferation; thus excluding osteoma formation. Hyperostosis in fish is a common lesion and it was recorded in 92 species 
belonging to 22 families and usually has a species specific pattern (SmithVaniz, Kaufman, and Glowacki 1995b). Many hypotheses may explain fish hyperostosis due to pollution, disease problems or genetic factors (Meunier, Gaudant, and Bonelli 2010), but the records of such lesions in many fish families and species exclude the assumption of genetic predisposition. Thus, the actual cause is still unclear. Our histopathological findings were somewhat consistent with the findings of Meunier, Gaudant, and Bonelli (2010); who described the pathological lesions of hyperostosis as spongy bone, increased periosteal osteogenesis combined to resorption that creates many vascular cavities. The examination of hyperostotic swelling in this study added noted some other findings including the aggregation of fat cells in some of the bone spaces in the center of the hyperosteoid tissue. In this regard, the role of the fish spines as a fat reservoir in some fish species has been fully discussed for many years. Wilson (1939) detailed the role of the fish skeleton as a fat depot particularly in the spongy part of the vertebrae and their hollows are frequently heavily laden with fat, and so are the grooves and canals of the neural and haemal spines. The adipose tissue is often present around the bones, however, due to the difficulty of sectioning this region, it has not been examined in histological detail.

In our study, the presence of fat cells in the cavities of the hyperostotic swelling together with the white granular contents in the center of such lesions may indicate evidence of abnormal fat metabolism which might occur as a result of some physiological disturbances during spawning, migration or changes in the nutritional behavior of these two fish species. However, Sutharshin, Sivashanth, and Thulasitha (2013) have paid attention to lipid changes in relation to maturation and spawning of $S$. lysan, the same fish that showed hyperostosis in our study. Also, Boglione et al. (2013) have demonstrated that different nutrients including lipids are responsible for the appearance of skeletal anomalies. Recently, Hemingway and Scarnecchia (2017) have confirmed the role of life history differences, such as growing season in the lipid metabolism in different tissues of paddlefish Polyodon spatbula.

\section{Conclusion}

The present study concluded that Scomberoides lysan and Pomacanthus sextriatus have a high prevalence of hyperostosis in the El- Jubail province of Saudi Arabia. The pathological lesions of hyperostosis in these two fish species are typically characteristic. Further epidemiological studies are required to make correlations between hyperostosis and other physiological factors such as migration, maturation and spawning. Also, genetic predisposition cannot be neglected. 
This is an open-access article distributed under the terms of the Creative Commons Attribution 4.0

International License (CCBY-4.0). View this license's legal deed at http://creativecommons.org/licenses/ by/4.0 and legal code at http://creativecommons.org/licenses/by/4.0/legalcode for more information. 


\section{REFERENCES}

Boglione, C., E. Gisbert, P. Gavaia, P.E. Witten, M. Moren, Fontagn S, and G. Koumoundouros. 2013. "Skeletal Anomalies in Reared European Fish Larvae and Juveniles. Part 2: Main Typologies, Occurrences and Causative Factors." Reviews in Aquaculture 5 (Suppl. 1): S121-67.

Davesne, Donald, François J. Meunier, Armin D. Schmitt, Matt Friedman, Olga Otero, and Roger B. J. Benson. 2019. "The Phylogenetic Origin and Evolution of Acellular Bone in Teleost Fishes: Insights into Osteocyte Function in Bone Metabolism.” Biological Reviews 94 (March): 1338-63. https://doi.org/10.1111/brv.12505.

Giarratana, Filippo, Anna Ruolo, Daniele Muscolino, Fabio Marino, Michele Gallo, and Antonio Panebianco. 2012. "Occurrence of Hyperostotic Pterygiophores in the Silver Scabbardfish, Lepidopus Caudatus (Actinopterygii: Perciformes: Trichiuridae).” Acta Ichthyologica Et Piscatoria 42 (3): 233-37. https://doi.org/10.3750/aip2011.42.3.07.

Grabda, Eugeniusz. 1982. "Fungi-Related Outgrowths on Pterygophores of Single Fins of Lepidopus Caudatus (Euphrasen, 1788) (Pisces: Trichiuridae).” Acta Ichthyologica et Piscatoria 12 (1): 87-105. https://doi.org/10.3750/aip1982.12.1.07.

Gualdie, R. W., and Z. Czochanska. 1990. "Hyperostotic Bones from the New Zealand Snapper Chrysophys Auratus (Sparidae).” Fishery Bulletin 88: 201-6.

Hemingway, R. J., and D. L. Scarnecchia. 2017. "Lipid Acquisition and Retention in Tissues of Spawning Adult Paddlefish Polyodon Spathula (Walbaum, 1792) in Relation to Extended and Compressed Life History Patterns in Two River-Reservoir Systems.” Journal of Applied Icbthyology 34: 42-48.

Huysseune, A. 2000. "Skeletal System.” In The Laboratory Fish, edited by G. Ostrander, 307-17. San Diego: Academic Press. https://doi.org/10.1016/b978-012529650-2/50024-x.

Jawad, Laith A. 2013. "Hyperostosis in Three Fish Species Collected from the Sea of Oman." The Anatomical Record 296 (8): 1145-47. https://doi.org/10.1002/ar.22728.

McGrouther, M. A. 1994. “Swollen Fish Bones.” Australian Natural History 24 (11): 1-79.

Meunier, F. J. 1987. "Os Cellulaire, Os Acellulaire et Tissus Dérivés Chez Les Ostéichthyens: Les Phénomènes de l'acellularisation et de La Perte de Minéralisation.” L'Année Biologique 26: 201-33.

_-_. 1989. "The Acellularisation Process in Osteichthyan Bone." In Trends in Vertebrate Morphology: Proceedings of the 2nd International Symposium on Vertebrate Morphology, 443-46. Vienna.

Meunier, F. J., J. Gaudant, and E. Bonelli. 2010. "Morphological and Histological Study of the Hyperostosis of Lepidopus Albyi (Sauvage, 1870), a Fossil Trichiuridae from the Tortonian (Upper Miocene) of Piedmont (Italy).” Cybium 34 (3): 293-301.

Roberts, R. J., D. A. Smail, and E. S. Munro. 2012. "Laboratory Methods.” In Fish Pathology, 4th ed., 439-81. Oxford, United Kingdom: Wiley-Blackwell. https://doi.org/10.1002/ 9781118222942.ch12.

Shahar, Ron, and Mason N. Dean. 2013. "The Enigmas of Bone without Osteocytes." BoneKEy Reports 2 (May): 343. https://doi.org/10.1038/bonekey.2013.77.

Smith-Vaniz, William F., and K. E. Carpenter. 2007. "Review of the Crevallejacks, Caranx Hippos Complex (Teleostei: Carangidae), with a Description of a New Species from West Africa.” Fishery Bulletin 105: 207-33.

Smith-Vaniz, William F., L. S. Kaufman, and J. Glowacki. 1995a. Sample Records for Marine Fish; Species-Specific Patterns of Hyperostosis in Marine Teleost Fishes. USGS Publications Warehouse. 
- - . 1995b. “Species-Specific Patterns of Hyperostosis in Marine Teleost Fishes.” Marine Biology 121 (4): 573-80. https://doi.org/10.1007/bf00349291.

Sutharshin, S., K. Sivashanth, and W. S. Thulasitha. 2013. "Lipid Changes in Relation to Maturation and Spawning of Tropical Double Spotted Queenfish, Scomberoides Lysan (Forsskål, 1775).” Asian Journal of Animal and Veterinary Advances 8 (4): 555-70. https://doi.org/10.3923/ ajava.2013.555.570.

Wilson, Douglas P. 1939. "Seasonal Variations in the Fat Content of the Flounder, Pleuronectes Flesus L.” Journal of the Marine Biological Association of the United Kingdom 23 (2): 361-79. https://doi.org/10.1017/s0025315400013953.

Witten, P. E., A. Huysseune, T. A. Franz-Odendaal, T. Fedak, M. K. Vickaryous, A. Cole, and B. K. Hall. 2004. "Acellular Teleost Bone: Dead or Alive, Primitive or Derived?" The Palaeontological Association Newsletter 55: 37-41. 